\title{
Urdimento
}

Revista de Estudos em Artes Cênicas

E-ISSN: 2358.6958

\section{O auto-teatro de Hélio Oiticica: provocações de uma arte ambiental}

\author{
Everton Lampe de Araujo
}

\section{Para citar este artigo:}

ARAUJO, Everton Lampe de. O auto-teatro de Hélio

Oiticica: provocações de uma arte ambiental.

Urdimento, Florianópolis, v. 2, n. 38, ago./set. 2020.

DOI: http:/dx.doi.org/10.5965/14145731023820200007

Este artigo passou pelo Plagiarism Detection Software | iThenticate 


\title{
auto-teatro de Hélio Oiticica: provocações de uma arte ambiental
}

\author{
Everton Lampe de Araujo
}

\begin{abstract}
Resumo
Este artigo propõe um debate atual sobre espaço cênico a partir do artista brasileiro Hélio Oiticica e de suas contribuições para a ampla noção de arte ambiental em suas invenções, através da aproximação da performance, com atenção ao corpo e ao convívio. O artista subverte os limites das linguagens artísticas, a fim de experimentar os conflitos evidenciados entre arte e realidade. Ao cunhar a noção de auto-teatro, é possível concluir, junto de outros autores, que Oiticica construiu um caminho das telas aos corpos, considerando a instauração do ambiente através da dimensão arquitetural que foi acionada por seu interesse pela tridimensionalidade. Em seguida ele tratará da libertação da cor de suportes estáticos até a compreensão do espaço enquanto fenômeno social junto da abertura radical para a invenção de outros participantes em suas proposições, indo além da participação.
\end{abstract}

Palavras-chave: Arte ambiental. Corpo. Espaço. Performance. Convívio.

Hélio Oiticica's auto-teatro: provocations of an environmental art

\begin{abstract}
This article proposes a current debate on scenic space. The Brazilian artist Hélio Oiticica treated the space and the notion of environmental art in his inventions, through the approximation of the performance, with attention to the body and the social life. The artist subverted the limits of artistic languages in order to experience the conflicts between art and reality. By coining the notion of self-theater, it is possible to conclude, along with other authors, that Oiticica built a path from screens to bodies, considering the establishment of the environment through the architectural dimension that was triggered by his interest in three-dimensionality. Then he will deal with the liberation of color from static supports until the understanding of space as a social phenomenon along with the radical opening for the invention of other participants in his propositions, going beyond participation.
\end{abstract}

Keywords: Environmental art. Body. Space, Performance. Conviviality.

1 Arte Educador formado na Universidade Federal de Ouro Preto (UFOP - G). Licenciatura em Artes cênicas e dança na Université Lille 3. Mestrado no Programa de Pós-Graduação em Teatro e Doutorando em Teatro (PPGT - UDESC). tinho440@hotmail.com 
A noção de mundo-abrigo ${ }^{2}$ nascida das experiências ambientais de Hélio Oiticica, aponta para a necessidade de se pensar o lazer para além do entretenimento proposto pelo mundo-espetáculo, uma vez que o lazer do mundoespetáculo estaria condicionado pela indústria cultural ${ }^{3}$ e em oposição ao trabalho, divergindo do que o artista buscou na junção de invenção e prazer, enquanto lazer e também como trabalho.

O viver experimental proposto por Oiticica o leva para um lugar cada vez mais radical, quer em relação à produção artística quer em sua própria vida, territórios inseparáveis que reafirmam o fim da dicotomia lazer/prazer possibilitada pelas fissuras utópicas que as vezes a arte consegue instaurar no mundo.

Trata-se de uma aproximação bastante pessoal das teses emanadas pela Internacional Situacionista, de Debord, em contraponto às pulsões emanadas pela sociedade do espetáculo, um modo radical de viver na deriva e à margem do sistema de poder que a sustenta. Para o Situacionista Ken Knab (2003, p. 57):

A melhor "arte radical" se manifesta quando é, ao mesmo tempo, positiva e crítica. Quando ataca a alienação da vida moderna, ela nos adverte simultaneamente das potencialidades poéticas ocultas dentro dela. Mais que reforçar nossa tendência em evocar a autocompaixão, estimula nossa resistência, nos permite rir tanto de nossos próprios problemas quanto da estupidez das forças de "ordem".

É possível considerar, a partir desta perspectiva de arte radical proposta pela

2 "Sobre a noção de mundo-abrigo: "[...]. Mundo como campo experimental significa: experimental como exercício para um tipo de comportamento-plenitude que ao menos tenda a uma estrutura de lazer como prazer oposto à atual de lazer como dessublimação programada que sustenta período-horas de trabalhoprodução alienado. [...]. A produção numa posição experimental não é produção oposta ao lazer mas lazer tornado produção. (Oiticica, 1973, p. 08).

\footnotetext{
${ }^{3}$ Sobre a indústria cultural: "Os interessados adoram explicar a indústria cultural em termos tecnológicos. A participação de milhões em tal indústria imporia métodos de reprodução que, por seu turno, fazem com que inevitavelmente, em numerosos locais, necessidades iguais sejam satisfeitas com produtos estandardizados. O contraste técnico entre poucos centros de produção e uma recepção difusa exigiria, por força das coisas, organização e planificação da parte dos detentores. Os clichês seriam causados pelas necessidades dos consumidores: por isso seriam aceitos sem oposição. Na realidade, é por causa desse círculo de manipulações e necessidades derivadas que a unidade do sistema torna-se cada vez mais impermeável. O que não se diz é que o ambiente em que a técnica adquire tanto poder sobre a sociedade encarna o próprio poder dos economicamente mais fortes sobre a mesma sociedade. A racionalidade técnica hoje é a racionalidade da própria dominação, é o caráter repressivo da sociedade que se auto-aliena." (Adorno, 2002, p. 06).
} 
Internacional Situacionista, que o lazer/prazer proposto por Hélio Oiticica invoca público/propositor para uma experiência de expansão de suas sensações, sobre outras possibilidades de viver. " O importante é revelar o contraste entre as presentes condições e as presentes possibilidades, e transmitir às pessoas um maior apego e um maior desejo pela vida real" (Knab, 2003, p. 55). De modo que nenhuma experiência seria mais efetiva que a própria vivência dos sujeitos experimentando possibilidades na realidade social.

Ao tratar de arte nessa mesma realidade, envolvendo cidades, vida cotidiana, fluxos e relações, é comum se deparar com noções como espaço e ambiente, assim como os termos estrutura e arquitetura, que Hélio Oiticica agrega em seu trabalho e contribui numa práxis valiosa, a partir do que chamou de arte ambiental ${ }^{4}$. O artista aponta em quase três décadas de invenção, para a noção de auto-teatro ${ }^{5}$, que dentre outras especificidades, trata da passagem da noção de ambiente centralizada no objeto ou estrutura rígida, para as experimentações corporais enquanto interesse de investigação.

Através da arte ambiental, a diluição de fronteiras entre arte e vida, bem como entre público e artista, já vinha sendo experimentada anteriormente por Oiticica nos anos 60 quando ele já evidenciava seu salto do quadro para o espaço por meio do interesse pela tridimensionalidade, que é concretizada nas obras Bilaterais 1959 (óleo sobre madeira) e Relevos espaciais 1959 (acrílico sobre madeira), estruturas tridimensionais criadas majoritariamente por madeiras, onde Hélio Oiticica investe em diferentes modos de apresentação, que, em comum, tinham o interesse de estabelecer relações entre cor e luz, mais especificamente por investigar o possível movimento das cores tendo o espaço/forma como modo possível de materializar este movimento, com ênfase para a interferência da luz e da posição do corpo em relação à obra.

Hélio Oiticica e a Arte ambiental: "Está aí a chave do que será o que chamo de 'arte ambiental': o eternamente móvel, transformável, que se estrutura pelo ato do espectador e o estático, que é também transformável a seu modo, dependendo do ambiente em que esteja participando como estrutura. (Oiticica, 1986, p. 75).

5 Esse não é um conceito definido por Hélio Oiticica a partir de uma única ideia, mas se dá por um conjunto de práticas e reflexões a ser desenvolvido nesse artigo, desde a noção de Arte Ambiental, até a radicalidade na participação proposta por Oiticica, a partir dos anos de 1970. 
Já os Núcleos ou Bilateral Equali (1960), marcaram, em seu percurso, a ruptura com o quadro e a libertação das cores no espaço, através de placas instaladas separadamente e depois em conjunto, o Grande Núcleo (1961), formando um labirinto. Os Núcleos já apresentavam a condição de que o público criasse a partir da sua experiência vivencial ao caminhar pelo espaço, uma percepção do trabalho mediada por um tempo próprio, em um percurso que não possui lugar fixo para começar ou terminar, como um verdadeiro labirinto.

Ao se envolver com os cadernos de anotações de Oiticica, é possível afirmar que pelo menos desde 1961, surgem oficializadas suas preocupações e interesses pela participação do público e, mais do que isso, pelas provocações que a criação artística pode sugerir rumo ao experimental que só é possível com a libertação dos procedimentos já conhecidos, abrindo desde cedo caminhos para o acaso e o desconhecido em suas proposições.

Nesta última semana lancei em realização o primeiro núcleo "improviso", outra modalidade do núcleo. [...]. O núcleo improviso consiste na realização do núcleo no espaço, sem "maquetes anteriores, ou elaboração demorada, pois há a necessidade de realizá-lo rapidamente, desde o seu corte até a cor, como que de improviso. Essa necessidade de improvisar é uma das características mais importantes da arte contemporânea, mesmo dentro de uma expressão que se baseia na elaboração. (Oiticica, 1961, s/p).

O improviso ganha espaço nas criações de Oiticica, pois improvisar aponta para as possibilidades ainda não conhecidas de invenção, estas que se apresentam como alternativas à elaboração inicial da obra ou que revelam sua condição inesgotável em função da abordagem realizada pelo público que transforma o desejo inicial do artista.

Desde os primeiros Bólides (1963) estruturas em tamanho miniatura e depois projetadas para acolhimento do corpo, em Éden (1967), depois em Ninhos (1970), através de diferentes materialidades, as proposições buscavam gestar sensações de acolhimento, acionar memórias e espontaneidade dos participantes, onde eram usadas palhas, madeiras, tecidos, luminárias, tendas e camas que projetadas como receptáculos de possibilidades abertas do comportamento, tinham a finalidade de 
serem espaços para a livre experimentação do corpo, em que ao vivenciar o ambiente, os participantes pudessem encontrar uma diversidade de sensações bastante distintas daquelas experimentadas nas relações massificantes de seu cotidiano.

O que tínhamos nos anos 1970 e contemporaneamente sob o influxo da performance, é a necessidade de um ambiente que aloje e circunscreva tais experimentações, alavancando-as a um estágio ainda mais radical, onde nem mesmo uma proposição inicial realizada por um artista necessitaria acontecer.

Tais desejos e ambições vão ser desenvolvidos a partir do auto-teatro, quando os papeis serão embaralhados para dar início a uma nova proposta de jogo, com os riscos implícitos ao que tudo pode acontecer, inclusive nada.

No início dos anos 1970, em entrevista a Gisele Campos no Jornal do Brasil, intitulada "Uma arte sem medo", Hélio Oiticica revela seu desejo de experiência teatral aberta:

Quero procurar todos os meios de comunicação que sejam o desenvolvimento das experiências que nasceram da arte de participação e sensorial. Por exemplo, eu tenho uma ideia de uma experiência teatral aberta, na qual não existe plateia ou espectadores, mas simplesmente ideias e participantes nas ideias. Em música é fácil, ela própria estabelece essa relação. Em teatro, muitas experiências foram feitas, mas permanece a distância psíquica. A meu ver, o fato de se agredir o público não resolve nada. Foi importante, mas acaba virando redundância". (Oiticica; Vieira, 2010, p. 92).

O teatro e a performance, como partes integrantes e às vezes até indiscerníveis na cena contemporânea, provocaram Oiticica nos anos 70, a partir das tentativas de reinvenção do acontecimento artístico.

Este sentimento e desejo do artista posteriormente vai reverberar em uma necessidade de discussão sobre como criar esta "experiência teatral aberta" que, seguindo suas proposições, vinham sendo pensadas junto da criação de ambientes para a experiência do corpo.

Para isso o pesquisador David Sperling contribui de maneira importante para a compreensão do ambiente na obra de Oiticica, afirmando que: 


\begin{abstract}
A arquitetura como manifestação ambiental, no sentido de Oiticica, é, pois, estruturação de um campo e não formatação de uma forma; é abertura à construção pela experiência vivencial e não definição por completo em uma abstração projetual. Da "representação" para a "presentificação". Vai além do espaço "pronto", pois compõe-se de elementos "transformáveis" e "para fazer", gradientes de abertura para a continuidade processual. (Sperling, 2008, p. 126).
\end{abstract}

Por isso é possível compreender inclusive as capas parangolés (1965) como elementos dentro destas manifestações ambientais, que não se tratam somente da criação de Núcleos ou Bólides, mas também das materialidades das capas que se modificam no vestir, incorporar, pelo próprio movimento do corpo, enquanto se retroalimentam, através do dançar, ampliando a estruturação ambiental com ênfase nas experiências corporais de participação ao detalhar a passagem de Oiticica do plano estrutural ao sensorial. Não se tratando de um abandono das materialidades e sim da reinvenção e usos diversos, através de diferentes elaborações não hierárquicas na relação entre materialidades e pessoas.

Assim, esta reflexão busca contribuir na sistematização da noção de arte ambiental de Oiticica culminante, mas não totalizada, na ideia de auto-teatro. E com isso, suscitar provocações para a cena contemporânea, das possibilidades de pensar, discutir e praticar espaços, com ênfase na participação e experiências corporais, pensando ambiente como conjunto de situações, assim como a possibilidade de ampliar o referencial brasileiro para o debate de formulações espaciais nas artes.

Para tanto, se torna importante acompanhar a perspectiva crítica de passagem da noção de espaço arquitetônico para a experiência no espaço arquitetural, com que o pesquisador David Sperling vai posicionar as criações de Oiticica e que auxilia na compreensão desta arte ambiental.

Segundo (Sperling, 2008, p.135), a situação arquitetural é “[...] constantemente estruturada pela experiência vivencial de um tempo e de um lugar, tendo em si como potência outras situações". Isso porque: "A criação objetificada, o espaço contido na abstração das formas geométricas e feito integralmente para sua posterior experiência, diz respeito ao espaço arquitetônico". Já o espaço 
arquitetural é, para (Sperling, 2009, p.130-131): “[...] espaço topológico que se estrutura por relações entre corpos e porções de espaço. O primeiro, [arquitetônico] a cristalização de uma forma geométrica, o segundo, [arquitetural] o homeomorfismo ${ }^{6}$ de um sistema de relações espaciais”. É comum perceber que grande parte dos estudos sobre espaço arquitetônico vai tratar de espaços préelaborados para as experiências do corpo, enquanto o espaço arquitetural, possibilita aberturas de maior expressão não anteriormente projetadas para uso do corpo, possibilitando inclusive sua própria efemeridade e podendo acontecer enquanto instauração.

O ambiente não é a forma, mas um campo de forças e, com isso, é possível afirmar a produção de ambientes também pela criação de experiências vivenciais não determinadas e não apenas pela força de objetos. Oiticica apresenta mais algumas considerações sobre seu desejo, imbricadas enquanto experiência:

O que eu quero na minha coisa é uma prática, mas que foge do sentido ritual, porque os meios de introdução das pessoas nesta prática não estão submetidos a formas ritualísticas, que poderiam cair numa coisa antiga. São antes baseadas em proposições abertas ligadas ao comportamento de cada pessoa. (Oiticica, 2010, p. 92).

Um interesse similar às ideias de Oiticica vinha sendo experimentado nos trabalhos do Performance Group, em Nova York, que como lugar de pesquisa de Richard Schechner além de suas experiências com outros grupos de trabalho, culminaram na publicação do livro e na elaboração do conceito de environmental theater (1973) o teatro ambiental que buscou propor mudanças radicais frente às estruturas tradicionais das artes cênicas no sentido de participação.

Efetivo aqui desdobramentos das pistas $^{7}$ apontadas pelo ensaísta Edélcio

${ }^{6}$ Em topologia, pertencente ao campo das geometrias não-euclidianas, homeomorfismos são transformações espaciais contínuas que podem ser continuamente desfeitas. Nelas, algumas propriedades são invariantes independentemente da alteração da forma geométrica. Sobre este assunto e suas implicações na arquitetura ver David. Sperling (2006), Arquiteturas contínuas e topologias: similaridades em processo.

O ensaísta Edélcio Mostaço, iniciou investigações relativas as aproximações entre a arte ambiental de Hélio Oiticica e o environmental theater de Schechner e abre um vasto número de possibilidades de relação entre os artistas, começando pelas referências que acompanhavam ambos em suas investigações: "É difícil saber se Oiticica conhecia as experiências de Schechner, mas ambos, sem dúvida foram movidos por alguns estímulos em comum. Duchamp, Artaud, Klee e a Bauhaus são citados por ambos em seus escritos, 
Mostaço sobre aproximações entre Oiticica e Schechner a fim de buscar compreender um pouco mais como a interface com o teatro ampliou as experimentações de Oiticica no caminho do auto-teatro, desde uma ideia sem forma, até a criação dos novos Penetráveis Magic Square. Com isso, é fato que a imprevisibilidade toma conta do jogo, noção próxima daquilo que Oiticica vinha nomeando como experimental e que ultrapassa dicotomias como certo ou errado, no sentido de fracasso ou sucesso de um acontecimento.

A obra Tropicália (1967), por exemplo, como uma das mais conhecidas dentro do projeto ambiental de Oiticica, trazia materialidades que compunham uma série de situações não lineares, como placas, avisos, plantas, areia, animais, estruturas de madeira em que o público se relacionava explorando a obra a partir de encontro com diferentes materialidades que compunham o Tropical. O que acontece, diferente de Tropicália, a partir dos anos 70 é que Oiticica busca radicalizar cada vez mais suas propostas ambientais, pois uma vez que o público passa a integrar a obra como criador, já não interessaria para Oiticica a criação de ambientes que tivessem a mediação de um artista ou de um acontecimento artístico instaurado para se concretizar, de modo que sua mirada para a arte ambiental, a partir do auto-teatro, passa a se tornar a criação de ambientes vazios, a serem preenchidos pelas proposições e desejos de quem estivesse nestes espaços:

Não estou querendo criar obras, ou transformar ingenuamente ambientes em obras: a estrutura-abrigo-labirinto ou que forma tomar é o lugar onde proposições abertas devam ocorrer, como uma prática, não-ritualística, o que coloco em situação como se fora 'um circo sem ritual ou espetáculo', um auto-teatro, onde os papéis estão embaralhados: performer, espectador, ação, nada disso possui lugar ou tempo privilegiado: todas as tarefas se dão em aberto, ao mesmo tempo em lugares diferentes; não há também a urgência de criar nada: a autoperformance de cada um seria a tarefa-goal que liga tudo. (Oiticica, 1971 in Braga, 2008, p. 321).

De modo diferente em relação ao Performance Group, de Schechner, por exemplo, o auto-teatro de Oiticica não considera a aproximação do público com o 
acontecimento como característica transgressora, pois para ele estes papeis estariam desde o início embaralhados, sem lugar ou tempo privilegiados, de modo que algo inclusive pudesse ou não acontecer.

Aos poucos, Oiticica chega à formulação de que o auto-teatro deveria acontecer num espaço público, de modo a coletivizar ainda mais o lugar de criação e lazer, o que fazia com que suas ideias ganhassem dimensões utópicas, embora muitos de seus aspectos pudessem ser verdadeiramente vivenciados.

No livro Environmental Theater, de 1973, Schechner traz algumas reflexões e afirmações que reforçam diferenças entre o teatro ambiental e o auto-teatro.

O que acontece com uma performance quando os acordos habituais entre performer e espectador são quebrados? O que acontece quando performers e espectadores realmente fazem contato? Quando eles conversam uns com os outros e se tocam? Atravessando as fronteiras entre teatro e política, arte e vida, evento performático e evento social, palco e auditório? A participação do público expande o campo do que é uma performance, porque a participação do público ocorre precisamente no ponto em que a performance é derrubada e se torna um evento social. Em outras palavras, a participação é incompatível com a idéia de um auto-conteúdo, autônomo, início-meioe-final da obra. O Performance Group não falou muito sobre a participação do público enquanto preparava "Dioniso" em 69. À medida que trabalhávamos, mais cenas precisavam da colaboração ativa da platéia, e logo quase toda a peça estava aberta ao público. Em qualquer noite, poderíamos esperar que os espectadores se juntassem a perfomance em um ponto ou outro. Os momentos participativos mais extraordinários aconteceram quando as pessoas chegavam ao teatro em grupos, ou quando os indivíduos cediam à performance tão plenamente que, durante perfomance, se juntaram ao Grupo como se fossem membros. (Schechner, 1994, p. 40) ${ }^{8}$.

8 What happens to a performance when the usual agreements between performer and spectator are broken? What happens when performers and spectators actually make contact? When they talk to each other and touch? Crossing the boundaries between theater and politics, art and life, performance event and social event, stage and auditorium? Audience participation expands the field of what a performance is, because audience participation takes place precisely at the point where the performance breaks down and becomes a social event. In other words, participation is incompatible with the idea of a self-contained, autonomous, beginning-middle-and-end artwork. The Performance Group didn't talk much about audience participation while preparing Dionysus in 69. As we worked, more scenes needed the active collaboration of the audience, and soon nearly all of the play was open to the audience. In any given night we could expect spectators to join in the performance at one point or another. The most extraordinary participatory moments happened when people came to the theater in groups, or when individuals gave over to the performance so fully that for the duration of the performance they joined the Group as if they were members. (Tradução nossa) 
Ao ressaltar tais dados, Schechner evidencia a dimensão ficcional do teatro - mesmo o ambiental - quando demarca momentos de participação livre de espectadores frente a uma estrutura já pré-estabelecida. Ainda que nenhum acontecimento estético exista fora do meio social, este lugar da arte como território específico e geralmente controlado por seus realizadores, se afastava das proposições de Oiticica, pois uma das características que o tornam um artista singular foi o modo com que expôs as aberturas de suas proposições, para justamente derrubar as fronteiras entre arte e vida.

O auto-teatro torna-se um dos conceitos centrais para Oiticica, onde o "auto" supõe o corpo e a consciência de cada um no instante da realização, e o "teatro" a forma da relação desencadeada por esse jogo, mas não como representação ou desempenho de um papel, mais sim seu aspecto relacional, criando situações de envolvimento do próprio sujeito ou seus circunstantes, engendrando o acontecimento.

Ao invés de seguir com a utilização do termo performance, Oiticica cria um designativo para suas proposições em torno do auto-teatro, radicalizando a construção de uma relação num dado ambiente, onde só há acontecimento na medida em que há interesse propositivo por parte dos participantes desde o início da experimentação.

A pesquisadora Diana Taylor, junto de outros investigadores e artistas, problematiza desde os anos 1970, como a noção de performance vêm sendo discutida, repensada e relacionada com possíveis outras terminologias, dentre elas "arte acción", "el performance" ou "la performance", que implicam em uma apropriação pela língua espanhola em relação à performance anglo-saxã, abarcando uma discussão de gênero do próprio termo que, no francês antigo, surgiu como parformer, exécuter, accomplir ou parfaire ${ }^{9}$ e que vai se consolidar na segunda metade do século XX nos Estado Unidos como performance art.

Taylor reafirma nas discussões contemporâneas a importância tanto de apropriar-se da performance para a criação de novos termos que façam sentido

\footnotetext{
${ }^{9}$ Realizar, cumprir.
} 
para determinado artista e seu contexto social, como é o caso de Oiticica, assim como atenta para a potencialidade presente no fato de seguir utilizando um termo estrangeiro e intraduzível:

Performance' acarrea la posibilidad de un desafío, incluso de autodesafío, en sí mismo. Como término que connota simultáneamente un proceso, una práctica, una episteme, un modo de transmisión, una realización y un medio de intervenir en el mundo, excede ampliamente las posibilidades de las otras palabras que se ofrecen en su lugar. Además, el problema de intraductibilidad, según lo veo yo, es en realidad positivo, un bloqueo necesario que nos recuerda que 'nosotros'- ya sea desde nuestras diferentes disciplinas, o desde nuestros idiomas, o ubicaciones geográficas en América- no nos comprendemos de manera simple o sin problemas. Mi propuesta es que actuemos desde esa premisa- que no nos comprendemos mutuamente- y reconozcamos que cada esfuerzo en esa dirección necesita dirigirse en contra de nociones de acceso fácil, de descifrabilidad, y traductibilidad. Este obstáculo desafía no sólo a los hablantes de español o portugués que se enfrentan a una palabra extranjera, sino a los angloparlantes que creían que comprendían lo que significaba 'performance." (Taylor, 2001, p. 01).

No momento em que o auto-teatro é formulado enquanto ideia que repensa obra, espaço e representação, torna-se possível tomar, dentro das considerações de Oiticica, que seria este o termo empregado pelo artista para designar a performance, a partir de sua leitura e novo enquadramento para o termo, que vai culminar na criação do novos Penetráveis agora intitulados Magic Square.

Oiticica postula que para existir o auto-teatro seria necessário investir no espaço público como um lugar de experiência coletiva. É neste momento que seus penetráveis do início dos anos 60 são retomados na década seguinte, mas em outra perspectiva, não mais efêmeras e dentro de galerias e sim construções fixas ao ar livre, na busca de espaços outros que não a ditadura ${ }^{10}$ instaurada no Brasil, seguida do Al-5 em 1968.

10 No ano de 1967, diferentes iniciativas artísticas e sociais criaram no Brasil um forte movimento de contracultura que se opunha a ditadura instaurada no país, com suas especificidades, as ações colaboravam cada uma de modo singular para uma mudança social no país, que levavam em consideração tanto o campo estético como a própria luta armada e guerrilha social. dizia (Frederico Morais apud Freitas, 2007, p. 13) : " [...] Era em verdade, mais que uma forma de renovação dos estilos, uma "forma de comportamento", "uma atitude definida diante do mundo" ou ainda a própria "luta" entendida "como processo de vida" ". O comprometimento político com esta proposta de vanguarda vinha sendo elaborado por Hélio Oiticica em diálogo com diversos artistas que compuseram a Nova Objetividade brasileira, exposição no MAM do Rio de Janeiro em 1967 lançando um manifesto que propunha modificações da prática artística, agora em diálogo com a sociedade. 
Bom, ultimamente, em Nova York, eu entrei numa outra coisa que era um velho sonho meu, de criar estruturas que pudessem ser usadas por um grande número de público, que não fosse depender de alguém promover uma performance (trabalho de arte). Eu tava sentindo falta de uma coisa assim que de repente pudesse se concretizar rapidamente, fisicamente, que também não fosse mais a velha coisa da obra pela obra e a velha relação entre artista e a obra aberta, em nada disso. Quer dizer, o próprio dia a dia, pra mim, é a construção de uma obra, o dia completo é a obra. Como também não existe mais o movimento de vanguarda: cada dia, o dia a dia é a vanguarda, entende? Aí comecei a fazer um negócio assim de umas maquetes que fossem e pudessem ser uma praça... inclusive eu chamo de Magic Square é quadrado e é praça ao mesmo tempo. Que pudesse ser uma coisa que ficasse permanentemente ali, para uso público. (Oiticica, em entrevista para Cardoso, 1978).

Oiticica foi convidado a criar um projeto - não realizado - de revitalização do rio Tietê em São Paulo, onde sua proposição ficava mais clara e se aproximava da ideia de criação de praças públicas, estruturas fixas que pudessem ser apropriadas e desfrutadas permanentemente, garantindo a permanência de espaços de criação/lazer na vida social. Após sua morte, algumas das Magic Squares foram construídas, entre elas no Parque da Tijuca no RJ e no Museu Inhotim, em MG.

Figura 1- Penetráveis Magic Square em Inhotim (MG). Foto: Márcio Masselli

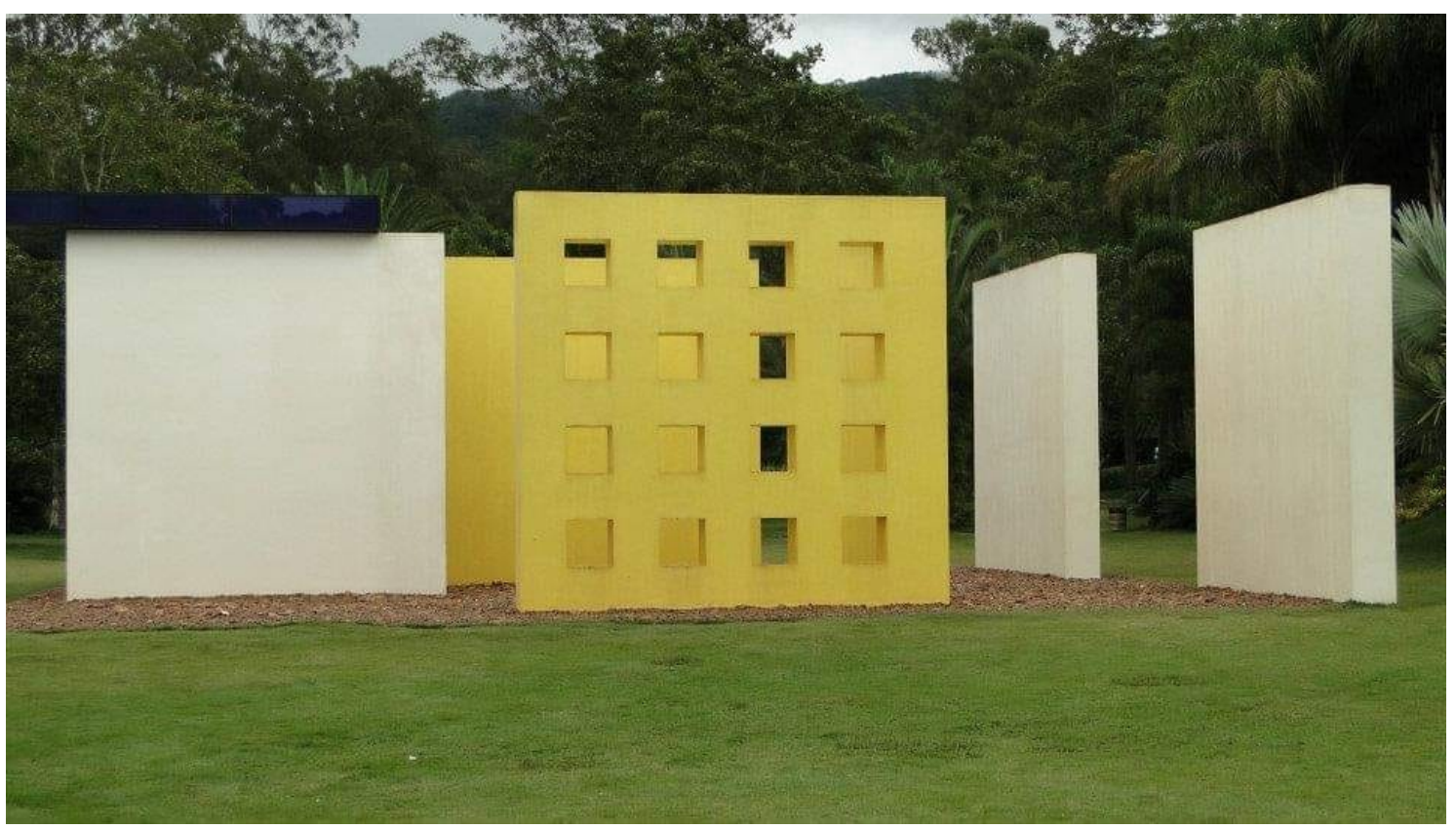


Estes novos Penetráveis, tornam-se um jogo a partir das linhas de Mondrian que, apropriadas pelo artista, retornam na discussão de liberdade das cores no espaço de 1961, mas com o foco nas relações que possam fazer emergir com o ambiente.

De maneira aberta e experimental, tais proposições compõem um jogo interminável onde múltiplas relações podem ser criadas, uma vez que suas formas trazem cores e materialidades dintintas para o caminhar ou o desenvolvimento de outras ações incluindo os Penetráveis.

Este cubo/praça é aberto, recebe as interferências naturais, produzindo sombras e formas que se modificam ao longo do dia, ampliando ainda mais as

O auto-teatro, a partir da criação dos novos Penetráveis, aproxima-se também das proposições presentes na estética relacional, discussão conceitual vinculada ao investigador Nicolas Bourriaud, que aproxima a arte da sociedade, através de diversos procedimentos na vida social. "Relacional (estética) Teoria estética que consiste em julgar as obras de arte em função das relações humanas que apresentam, produzem ou suscitam" (Bourriaud, 2007, p. 142). E ela só é possível a partir do interesse cada vez maior por uma arte relacional. "Relacional (arte) conjunto de práticas artísticas que tomam como ponto de partida teórico e prático o conjunto de relações humanas e seu contexto social, mais do que um espaço autônomo e privativo" (Bourriaud, 2007, p. 142). Com isso o artista Oiticica avança sobre os modos de relação radical que vai evidenciar.

Como visto anteriormente, a dimensão social que configura a concepção de Oiticica para os Penetráveis Magic Square se situa justamente em seu interesse de que elas fossem criadas em espaços públicos, desligadas de um procedimento específico de ritualização para experimentar o ambiente.

Se configurava como auto-teatro, um espaço relacional voltado ao público/participante para que algo acontecesse, papeis embaralhados entre público e artista. Considerações estas que também se aproximam do olhar de Bourriaud para o público na arte contemporânea. "É importante não mitificar a noção de público: a ideia de uma massa unitária tem mais a ver com uma estética 
fascista do que com experiências momentâneas em que cada um deve conservar sua identidade." (Bourriaud, 2007, p. 174).

Ainda sobre as especificidades, é possível notar pelas imagens que o mesmo projeto foi construído tanto em Minas Gerais como no Rio de Janeiro, com a diferença do piso e da paisagem: o primeiro composto com pedras no piso e em área com sol aberto; enquanto a segunda, no Rio de Janeiro, foi construída mantendo o chão de terra e envolto por diversas árvores.

Penetrável Magic Square № 5, De Luxe, de 1977: “[...] parece colorida surgindo na floresta, brotando da própria terra [...] fusão e transmutação dos laranjas, magentas, amarelos, brancos e azuis. Luzes e sombras também são cortadas por folhagens verdes. A arte de Hélio brota encoberta pela mata da tijuca [...] mergulho da "cor-luz" e natureza constituem um convite ao ambiental [...] Este trabalho é o ápice da cor que reinventa do espaço. [...] O Magic Square no 5, De Luxe é a realização [...] de uma nova realidade plástica [...] em que arquitetura, escultura e pintura estariam fundidas e não integradas. [...] é a culminância de um processo do início do século XX, de desmonte do quadro para conservar a pintura. Só que a pintura teve que abandonar o plano da tela e buscar no espaço físico do mundo (fundindo-se como arquitetura) aquilo que a representação perseguia como imagem. (Doctors, 2000, s/p).

A libertação das cores por esses espaços, se espalham enquanto ambiente e ganham fluência das mudanças constantes da luz solar, além da aproximação espacial das placas que alteram a percepção das cores umas das outras, criando tons e jogos de sombras. O ambiente a céu aberto, constrói e se modifica com a chuva, pelos ruídos externos, sons das pedras por todo o caminhar e convidam para a musicalidade, vozes, corpos, velocidades. O Penetrável Magic Square no5, surpreende na variedade de sensações provocadas enquanto labirinto, onde corpos em movimento se incorporam na experiência, formando um ambiente. Desde o silêncio e contemplação até o desejo de gritar em meio ao labirinto, a experiência se instaura, sem dúvida nenhuma, como um cubo mágico, espaço de jogo.

As experiências de Oiticica com o auto-teatro, bem como mais tarde faz a Estética Relacional, levam em consideração um movimento importante que não está somente na obra e suas especificidades como objeto. "A prática do artista, 
seu comportamento como produtor, determina a relação que mantém com sua obra. De outra maneira, o que o artista produz em primeiro lugar são relações entre pessoas e o mundo" (Bourriaud,2007, p. 51). Produzir relações pode ser pensado como procedimento fundamental na arte de quem em geral esteja prédisposto às vivências compartilhadas que contam com participação dos presentes para que algo aconteça, que por outro lado salta na também possibilidade implícita de nada acontecer.

Se o contexto de repressão da ditadura militar ou ainda se a desconfiança política da elaboração de discursos nas artes, por parte exclusivamente de artistas, resultou para Oiticica, na abertura das experiências artísticas para criação de outros participantes. Não parece superada a necessidade do questionamento dessa desintegração das posições rígidas de artista e público na instauração de experiências coletivas de criação.

Os interesses pelos riscos implicados em experiências abertas e inconclusas e com acionamento radical por parte de quaisquer participantes, provocam, ainda hoje, a possibilidade de investir em auto-teatro como proposta radical de criação, pois os mesmo negocia autorias, provocações e caminhos possíveis, de interesse cada vez maior de pesquisas sobre recepção, lugares do espectador na arte e procedimentos coletivos de criação.

O auto-teatro possibilita caminhos para essa arte ambiental participativa e escolhe cores, formas, materialidades, vazios, como princípios de tal integração, e a partir daí opta intencionalmente em não ser temático, podendo vir a ser, na própria experiência. Com isso, aponta um caminho, mas não o único, de aproximação entre pessoas e acontecimentos artísticos, pela sensorialidade. Reconhece elementos em que a participação pode acontecer com maior facilidade, e tem tendências de acolhimento de corpos cansados no capitalismo.

Desconfio se não estaria na falta de instâncias de participação e decisões coletivas na sociedade, parte do problema recorrente na arte de insistir na tentativa de propor e incentivar a participação. Talvez o interesse ainda em vida de Hélio Oiticica fosse de criar espaços de auto expressão e expressão coletiva, 
como projetos públicos, uma aposta na democratização da experimentação estética para além dos espaços institucionais de arte, reconhecendo em sua própria trajetória quão distante estaria a noção de lazer fora do capital.

O trabalho na vida comum, de modo geral, reluta contra qualquer emancipação dos sujeitos e está longe da perspectiva anarquista de educação integral, na qual inclusive, Oiticica era próximo. Neste sentido, oferecer a arte como alternativa concreta e pública se mostrou uma saída radical rumo as cidades que, não só imaginadas, desejam ser construídas e vividas.

\section{Referências}

ADORNO, Theodor. Indústria cultural e sociedade / Theodor W. Adorno; seleção de textos Jorge Mattos Brito de Almeida. Trad. por Juba Elisabeth Levy... [et a1.]. São Paulo: Paz e Terra, 2002.

BOURRIAUD, Nicolas. Estética Relacional. Buenos Aires: Ed. Adriana Hidalgo. 2007.

DOCTORS, Marcio. Espaço de Instalações Permanentes do Museu do Açude - Hélio Oiticica. Rio de Janeiro: Museu do Açude, 2000.

OITICICA FILHO, César; VIEIRA, Ingrid (Org.). Encontros Hélio Oiticica. Rio de Janeiro: Beco do Azougue Editorial, 2010.

OITICICA, Hélio. "Uma arte sem medo" In: OITICICA FILHO, César; VIEIRA, Ingrid (Org.). Encontros Hélio Oiticica. Rio de Janeiro: Beco do Azougue Editorial, 2010.

KNAB, Ken. A alegria da Revolução. Trad. Railton Sousa Guedes e Coletivo Periferia. 2003.

FREITAS, Artur. Contra-Arte: vanguardas, conceitualismo e arte de guerrilha - 1969 -1973. Tese de Doutorado. Pós- Graduação em História. Universidade Federal do Paraná. 2007.

MOSTAÇO, Edélcio. O Sol do novo mundo. Hélio Oiticica e o teatro ambiental. In: PARANHOS, K. (Org.). História, Teatro e Política. São Paulo: Ed. Boitempo, 2012.

OITICICA, Hélio. Arquivo 0194.73, 1973. Disponível em: http://54.232.114.233/extranet/enciclopedia/ho/detalhe/docs/dsp_imagem.cfm?na me=Normal/0194.73\%20p08\%20-\%20484.JPG. Acesso em: 12 jan. 2019. 
OITICICIA, Hélio. Aspiro ao grande labirinto. Rio de Janeiro: Rocco, 1986.

OITICICA, Hélio. Caderno de anotações de Hélio Oiticica: arquivo 0182.61. São Paulo, Itaú Cultural, 1961.

OITICICA, Hélio. Entrevista a Jary Cardoso. "Um mito Vadio". Folhetim, 05 nov. 1978.

SCHECHNER, Richard. Environmental Theater. The Applause Acting Series. New York. 1994.

SPERLING, David. Corpo + Arte = Arquitetura: Proposições de Hélio Oiticica e Lygia Clark. In: BRAGA, Paula (org.) Fios Soltos: a arte de Hélio Oiticica. São Paulo: Perspectiva, 2008. p.117 a 135.

TAYLOR, Diana. Hacia una definición de Performance. 2001. Disponível em: http://performancelogia.blogspot.mx/2007/08/hacia-una-definicin-deerformance.html. Aceso em: 04 jan. 2017.

Recebido em: 27/06/2020

Aprovado em: 29/07/2020 